\title{
Destruindo imagens: configurações midiáticas do iconoclasmo
}

\section{Alberto Klein}

\section{Resumo}

Este trabalho apresenta uma reflexão sobre 0 gesto iconoclasta e sua circunscrição no horizonte midiático. Além de discorrer historicamente sobre episódios de controvérsia em torno da imagem, são identificadas três características da nova condição midiática do iconoclasmo, a saber: a) a exigência de visibilidade; b) o paradoxo da destruição; e c) a circularidade midiática da memória. A perspectiva teórica adotada baseia-se na teoria da imagem de Hans Belting, além de se valer de contribuições do filósofo Bruno Latour.

\section{Palavras-chave}

Mídia. Iconoclasmo. Imagem.

\section{Alberto Klein | klein@uel.br}

Professor do Programa de Mestrado em Comunicação da Universidade Estadual de Londrina.

Este trabalho foi originalmente apresentado ao Grupo de Trabalho "Comunicação e Cultura", do XVI Encontro da Compós, na UTP, em Curitiba, PR, em junho de 2007. Para esta edição da revista, 0 artigo sofreu ampliações, além de várias modificações. Este artigo é fruto de reflexões em torno do projeto de pesquisa "Imagens em conflito: determinações do olhar no fotojornalismo pós-11 de setembro", financiado pelo CNPq.
A verdade é uma imagem, Mas não há imagem da verdade

Marie-José Mondszain

\section{$1 \mathrm{~A}$ atemporalidade de} idólatras e iconoclastas

Independentemente de seus suportes, as imagens, em situações determinadas, sempre se mantiveram como objeto de fascínio ou ódio. Os atos de cultuar imagens e destruí-las, posteriormente, inscrevem-se em um ciclo que revela disposições de espírito e atribuições de valor absolutamente contrárias em relação ao lugar que as imagens devem assumir na cultura. Seja qual for a atitude tomada, de fascinação ou repulsão, seja o gesto idólatra ou iconoclasta, em ambos os casos é o poder das imagens que é reiterado. Pois, para o iconoclasta, de nada adiantaria destruir imagens vazias ou insignificantes. Fosse este 0 caso, a atitude esperada seria o descaso.

Por mais poderoso que seja o culto, ou por mais violenta que seja a destruição, é estranho que os estudos de comunicação, raras vezes, abordem este tema, preferindo uma perspectiva de análise 
que contemple características dos novos suportes midiáticos das imagens, rupturas tecnológicas e suas funções sociais como a informação e 0 entretenimento, negligenciando os resíduos mágicos e encantatórios que prevalecem intactos em nossa sociedade midiática. Possivelmente, isso ocorre em função de uma confusão dominante no cenário da comunicação que toma o suporte pela imagem. Tornou-se comum falar em novas imagens na era digital, sendo que, na verdade, o que mudou foi o meio. Por mais simbiótica que seja a relação entre meio e imagem, a história das imagens distingue-se da história dos meios. Sobre isso, o estudioso da arte e da mídia Hans Belting afirma:

Imagem e mídia não permitem o mesmo tipo de narrativa ao descrever sua história. Uma história em sentido literal aplica-se somente à tecnologia visual; já as imagens resistem a qualquer história linear, pois elas não estão sujeitas a um progresso no mesmo grau. As imagens podem ser antigas mesmo quando ressurgem nas novas mídias. Também sabemos que elas envelhecem de formas diferentes das observadas no envelhecimento da mídia. Espera-se, geralmente, que as mídias sejam novas, enquanto as imagens mantêm sua vida, mesmo velhas, quando retornam entre as novas mídias. Temos certa dificuldade em reconstruir 0 caminho das imagens que migraram através de vários estágios implicados historicamente pelas mídias. As imagens parecem nômades no sentido de que elas estabelecem morada em uma mídia após a outra (2006, p.1).

Com a migração das imagens através dos suportes tecnológicos, o tempo vai perpetuando, do mesmo modo, mecanismos simbólicos ${ }^{1}$ próprios da imagem, que disparam, em determinadas épocas e culturas, tensões sobre sua condição sígnica, podendo eclodir em fenômenos de idolatria ou violência. 0 que sempre esteve em jogo é a distância guardada entre 0 signo e 0 referente, que muitas vezes se confundem e se devoram. "A imagem é o que ela representa", revelando-nos desde a préhistória a face demens do Homo sapiens, no dizer de Edgar Morin (1973). Um homem dado aos excessos e à loucura, cujo desequilíbrio expressa-se diante do êxtase da imagem. Tal como no mito de Pigmaleão, em que um artista se apaixona por uma estátua de mármore, fruto de sua criação. Vênus dá vida à estátua depois que 0 escultor lhe pede que conceda uma esposa segundo o modelo da obra dele.

\section{A questão está intrinsecamente ligada à} mediação. 0 encantamento do idólatra se dá porque a imagem se estabelece como único ou o mais forte instrumento de mediação com o sagrado, ou porque a própria mediação é suspensa pela incorporação do sagrado na natureza da imagem. Ela passa a fazer parte do sagrado. Vilém Flusser trata deste fenômeno como uma espécie de inversão do lugar das imagens diante do mundo: "0 homem, ao invés de se servir das imagens em função do mundo, passa a viver em função das imagens [...]. Para 0 idólatra, a realidade reflete imagens" (2002, p. 9). 
Para o iconoclasta, o problema também tem sua raiz na mediação. A imagem é uma mentira, farsa, não pode mediar o sagrado. A mediação, entretanto, se mantém, mas apenas na medida em que coloca a imagem como expressão de enganos, mentiras, dos deuses do outro ou de demônios. Assim, o seu trabalho é moralmente justificável. Aqui, a imagem não mantém da mesma forma um equilíbrio semiótico entre signo e objeto. Estes podem se aproximar ao ponto de a própria imagem confundir-se com os monstros que ela evoca.

\section{0 predomínio da palavra}

As insurreições contra imagens no universo cristão ilustram bem os conflitos em torno do estatuto da imagem. Em Bizâncio, nos séculos VIII e IX, em meio às ondas de violência e destruição de ícones, iniciada pelo Rei Leão III, o Segundo Concílio de Niceia, reunido no ano de 787, reiterava a magia das imagens, permitindo sua veneração. Em um de seus trechos se lia "porque a honra da imagem se dirige ao original". Com forte inspiração filosófica, o Concílio tentava reunir uma série de argumentos teológicos em favor da veneração das imagens, bem como estabelecia punições aos iconoclastas.

Assim, pois, quem se atreve pensar e a ensinar de outra maneira; ou seja, a deixar, seguindo os sacrílegos hereges, as tradições da Igreja, e inventar novidades, ou rechaçar algumas das coisas consagradas à Igreja: o Evangelho ou a figura da cruz, ou a pintura de uma imagem, ou uma santa relíquia de um mártir; [...] a empregar, ademais, em usos profanos os sagrados vasos ou os santos monastérios; se forem bispos ou clérigos, ordenamos que sejam depostos, se monges e laicos, que sejam separados da comunhão.(DENZINGER, 1963, p. 112).

Na Reforma Protestante do século XVI, a polêmica ressurge em meio a uma série de contestações de ordem teológica propostas pelos reformadores. Porém, entre eles não havia consenso acerca de uma doutrina das imagens e do destino que se devia dar a elas. Em geral, retomavam a condenação bíblica expressa no segundo mandamento da lei moisaica: "Não farás para ti imagem de escultura², nem semelhança alguma do que há em cima nos céus, nem embaixo da terra, nem nas águas embaixo da terra. Não as adorarás, nem lhes darás culto" (Êxodo, 20:4-5).

Martinho Lutero, responsável pela eclosão do movimento, não era simpático à quebra literal dos ícones e advogava uma mudança do espírito humano diante das imagens, restabelecendo um status semiótico de mera representação. Para ele, os ícones poderiam servir como instrumento de educação bíblica àqueles que não podiam ler. Tal postura, entretanto, não deixa de ser uma atitude iconoclasta, pelo seu teor racionalista, subjugando de certa maneira a imagem à palavra. Lucas Cranach, pintor renascentista, sob a instrução de Lutero, fez uma série de quadros com temas teológicos. 
Já, 0 artífice da Reforma em Zurique, Ulrico Zuínglio, não poupou esforços para eliminar todos os ícones das igrejas daquela cidade suíça. Para evitar tumultos, ele prescreveu um rígido ritual de destruição de imagens a portas fechadas, estabelecendo regras sobre como quebrá-las conforme sua mídia: afrescos, pinturas ou estátuas. Depois de treze dias que sua comissão de iconoclastas finalizou 0 serviço, o reformador suíço pode exclamar: "em Zurique temos igrejas positivamente luminosas; as paredes são maravilhosamente brancas" (DENZINGER, 1963, p.160).

Á remoção ordeira de imagens em Zurique contrasta 0 espetáculo da violência que tomou a cidade de Genebra. 0 s tumultos se deram às portas abertas, com toda a participação do povo. Estátuas com cabeças decepadas eram expostas nas ruas, a fim de mostrar que não possuíam poder algum. Para o dia da fúria iconoclasta, foi erigida uma placa de bronze no portão da cidade, dizendo que, naquela data, a igreja de Cristo havia sido restaurada e 0 anticristo romano expulso da cidade.

A colocação de uma placa de bronze no alto do portão, lugar tradicionalmente ocupado por imagens, sintetiza bem o espírito da Reforma, que procurou refugiar-se na palavra para escapar do fascínio das imagens. 0 teólogo João Calvino, que governou Genebra, poucas décadas depois do episódio, sentencia a exclusividade da mediação da palavra. 0 historiador Alain de Besançon, assim, explica a posição de Calvino: "Deus não ensina através de simulacros, mas através de sua própria palavra. Argumentar que as imagens servem de livros aos iletrados é simplesmente evidenciar que a igreja abdicou de sua obrigação de transmitir a palavra" (2000, p.187, tradução nossa). É possível que nunca, na história do Cristianismo, a tensão entre imagem e palavra tenha alcançado estes limites, mostrando como os episódios e a própria teologia dos iconoclastas resume-se a uma espécie de guerra de códigos. Nos países e cantões reformados, sobre a imagem prevaleceu a palavra, desembocando no que Vilém Flusser vai chamar de textolatria (2002, p. 11), quando o homem passa a viver em função dos textos.

Contudo, o próprio iconoclasta muitas vezes não consegue se desvencilhar da hipnose da imagem. A medida de violência desferida contra a imagem é ironicamente proporcional ao reconhecimento da medida de poder que ela exerce. 0 que se inverteu foi o sinal de positivo para negativo nos códigos culturais: não pode ser mais expressão do divino e do sagrado, mas sim, do anticristo, de baal e dos demônios. Trata-se tipicamente de um fenômeno de inversão semiótica de polaridades, possibilidade que se dá em muitos textos da cultura, conforme Ivan Bystrina (1995), sem, entretanto, que se suprima a tensão entre polaridades. Os mecanismos semióticos que sustentam as relações entre signo e objeto permanecem semelhantes tanto para os idólatras quanto para os iconoclastas, salientando o que 
diz Hans Belting: "O gênero humano nunca se libertou do poder das imagens, mas este poder tem sido exercido por diferentes imagens, de diferentes maneiras e épocas" (1994, p. 16, tradução nossa).

\section{A moldura midiática do iconoclasmo}

Certamente, nossa era midiática abriga tanto idólatras quanto iconoclastas. Se antes as querelas em torno da imagem eram expressas sobretudo no domínio da teologia e da religião, a cultura midiática criou seus próprios ídolos bem como atualizou rituais de destruição de imagens. A este respeito, o filósofo Bruno Latour questiona a possibilidade de superar as condições polarizadas de idólatras e iconoclastas. "Como é possível ir além deste ciclo de fascinação, repulsão, destruição, arrependimento, que é gerado pelo culto da imagem proibida?" (2002, p. 2, tradução nossa).

Partindo da pergunta de Latour, minha questão se fundamenta a partir do seguinte problema: como a nossa sociedade midiática reinscreve este ciclo, dando especificamente atenção aos novos contornos da ação iconoclasta.

A explosão das gigantescas estátuas dos budas pelo Talebã no Afeganistão, televisionada e exibida em telejornais do mundo inteiro, provocou reações apaixonadas no Ocidente, em virtude do valor histórico, cultural e estético das imagens. Mesmo que protestos externassem já este deslocamento da função de culto, é importante ressaltar, por outro lado, a postura indefectivelmente iconoclasta do grupo islâmico. Algumas questões podem emergir: por que registrar em imagens a destruição das estátuas? A memória e visibilidade midiática de algo que se quer apagar esconderiam uma finalidade política? Quais as implicações dessa nova moldura midiática do gesto iconoclasta?

A publicação de charges do profeta Maomé, em um jornal dinamarquês, no final de 2005, deu início, no universo muçulmano, a uma virulenta onda de violência e protestos. A infração era dupla: primeiro, a interpretação de que a caracterização do profeta pelo chargista era ofensiva; segundo, infringia a rígida proibição de se fazer qualquer imagem no âmbito da religião islâmica.

É interessante notar que as tensões entre 0 Ocidente Cristão e o Oriente Islâmico, acirradas com o gesto inaugural da destruição das Torres Gêmeas em 11 de setembro de 2001, dão 0 contexto dos novos episódios iconoclastas, enquadrados agora tanto pelo fotojornalismo quanto pela tela de televisão, além de outras mídias visuais. Neste novo quadro, parasita, residualmente em alguns casos, ainda a problemática inspiração religiosa, seja ela cristã ou muçulmana. Curioso lembrar que 0 empreendedor da "cruzada" contra o terrorismo, George W. Bush, um convicto fundamentalista evangélico, tenha sua matriz religiosa fundada nos iconoclastas da Reforma Protestante. 
Em uma sociedade, em que prevalece a ordem dos simulacros, descrita por Jean Baudrillard (1991), as soluções iconoclastas deverão sempre recorrer à mediação do espetáculo pelas mídias. Embora não seja tipicamente e tradicionalmente uma imagem, é plausível que a destruição do World Trade Center tenha obedecido a uma pauta midiática. Trata-se de um atentado não mais realizado nos subterrâneos do edifício (tal como perpetrado anteriormente), mas sim feito para a visibilidade das câmeras de televisão. De maneira irônica, Baudrillard expõe uma espécie de ambivalência neste ato de destruição, que poderia valer para qualquer outro ato iconoclasta. "0 fim no espaço material as fez entrar num espaço imaginário definitivo. Pela graça do terrorismo, tornaram-se 0 mais belo edifício mundial - 0 que com certeza não eram quando existiam" (2003, p. 17). Foi através de imagens de televisão que os espectros de Bin Laden e seu subordinado imediato, Al Zawari, vociferavam há pouco tempo novas ameaças. Pode também ser que, como as Torres Gêmeas, Bin Laden tenha morrido, embora sua imagem ainda assombre norte-americanos pelo videoteipe.

Outro personagem deste contexto pós-11 de setembro, Saddam Hussein, tornou-se a vítima preferencial na tentativa de superação do pesadelo das Torres Gêmeas. No plano midiático, foram adotadas soluções que resultaram uma espécie de destruição simbólica de sua imagem, a partir dos seguintes episódios: a) a derrubada de sua estátua em Bagdá, preparada para as câmeras de televisão; b) a sua captura em condições precárias em um buraco, flagrada por câmeras fotográficas; c) sua exposição somente em roupas íntimas em fotografias veiculadas por um jornal inglês; e d) a veiculação televisiva dos momentos finais que precederam seu enforcamento.

É possível, a partir destes episódios envolvendo Saddam Hussein, apontar algumas características presentes nesta reinscrição midiática do iconoclasmo, sem a preocupação de fechá-las ou esgotá-las. Minha proposta é identificálas para que sejam pontos de partida para trabalhos futuros. São três aspectos que inserem novos contornos e derivam desta nova condição midiática, a saber: a) a exigência de visibilidade; b) o paradoxo da destruição; e c) a circularidade midiática da memória.

A exigência de visibilidade. A destruição simbólica das imagens do outro requer visibilidade e espetáculo conferidos pelos meios de comunicação massivos. Em uma sociedade que apostou na extensão técnica da visão através de meios como fotografia, cinema, televisão e internet, é inevitável que a visibilidade se torne um valor cultural cada vez mais estimado. 0 impulso de levar para o plano da imagem todos os aspectos da vida humana tornou-se quase irresistível devido à disponibilidade dos meios e à virulência assumida pela reprodução de imagens midiáticas em nosso cotidiano. A vida social só se legitima pela visibilidade midiática, em um processo maníaco de devoração de imagens pelo 
homem, ou do homem pelas imagens (BAITELLO

JR., 2005), empurrando para as sombras da invisibilidade e da inexistência o que não está na mídia. Deste modo, a necessidade de destruir 0 outro através das imagens, ou as imagens do outro, não vai prescindir do espetáculo conferido pelas imagens midiáticas. Se em si mesmo a destruição das imagens comporta 0 espetáculo, ele agora vai ser exponencializado em sua visibilidade pela distribuição massiva proporcionada por jornais, TV e internet. Daí a necessidade de preparar o cenário e escolher os ângulos antes de perpetrar 0 ato. A derrubada da estátua de Saddam Hussein, sua captura em uma caverna $^{3}$, suas fotografias usando somente roupas íntimas e a exibição televisiva dos momentos que antecederam sua morte constituem uma verdadeira operação de mídia para garantir a eficiência de sua destruição, seja ela mesma física ou simbólica. 0 regime da visibilidade, assim, pauta não somente a construção e permanência de certas imagens no cenário midiático, mas também, e principalmente, os gestos destrutivos, que incidem muitas vezes sobre as mesmas imagens antes destacadas sob os holofotes. Se 0 investimento simbólico da imagem, sua alta capacidade de mobilização psíquica, exige na maioria dos casos, em sua sintetização imagética, alta visibilidade, por outro lado, a erradicação simbólica não poderá abdicar de processos e estratégias midiáticas que redundarão em grandes espetáculos de destruição. Tal é o destino dos símbolos que assombram: submeterem-se aos ritos iconoclastas intensificados pelas luzes dos meios visuais. Dado que o reconhecimento de um símbolo midiático depende da sua medida de visibilidade, sua capacidade de reaparição nos diversos meios, permitindo um sentido de onipresença, seu aniquilamento, por sua vez, deverá ter medida igual ou ainda maior de visibilidade, repetibilidade constante de imagens e onipresença quase absoluta. Isso se dá porque criar e manter símbolos são processos lentos e graduais, enquanto a destruição coloca-se como gesto instantâneo, com a mesma carga significativa, mas realizável em um único momento, daí advinda a dramaticidade de seu espetáculo.

\section{O paradoxo da destruição. Há uma flagrante} contradição nas operações iconoclastas da mídia. Em razão da transposição do mundo para 0 terreno das imagens midiáticas e do imperativo da visibilidade, o gesto iconoclasta será mais eficaz se for ampliado, emoldurado e perpetuado pelas imagens das mídias visuais. Ou seja, a sociedade midiática exige que se façam imagens de quebra de imagens. Para o iconoclasta midiático, não há contradições, pois ele mesmo pode ser um iconófilo diante de suas imagens.

3 Mesmo que não seja tipicamente um exemplo de gesto iconoclasta, os episódios envolvendo a captura, suas fotografias em roupas íntimas na prisão e finalmente sua morte, entendo, segundo a premissa do primado das imagens e da prevalência dos simulacros, Saddam era antes de tudo uma imagem midiaticamente construída. Daí a possibilidade de encarar estes episódios como parte integrante de um ritual iconoclasta operado pela mídia ocidental. 
Sua tarefa é dedicar-se à quebra de imagens do outro. Segundo Latour:

Por que será que todos os destruidores de imagens, os teoclastas, iconoclastas, ou ideoclastas também geraram uma fabulosa população de novas imagens, novos ícones, mediadores rejuvenescidos: grandes fluxos de mídia, ideias mais poderosas e ídolos mais fortes? Como se desfigurar algum objeto inevitavelmente gerasse novas faces, como se 0 desfiguramento (defacement) e o refiguramento (refacement) fossem necessariamente equivalentes (2002, p. 2, tradução nossa).

Tapar o rosto da estátua de Saddam Hussein com a bandeira norte-americana é um claro mecanismo de refiguração. Cobrir imagens com outras evidencia o desejo de extirpar ídolos da imaginação pública, uma questão sobretudo política. A refiguração entrevê a necessidade, não apenas de quebrar ou violentar, mas de jogar às sombras as imagens dos inimigos. Kamper nos lembra que "o poder do olhar manifesta-se naquilo que não é visto, que é deixado à margem como vítima da primeira distinção de uma visão focalizadora" (2003,p. 59). Mas também é dentro deste jogo de visibilidade que a carga simbólica pode se adensar na medida em que as imagens transcendem seu suporte. Assim como as Torres Gêmeas ficaram mais lindas depois de sua queda, para lembrar Baudrillard, é possível que a estátua de Saddam tenha ficado mais imponente depois da operação iconoclasta. Deste modo, seria o iconoclasmo possível? Seguindo o mesmo tom de Baudrillard, Belting afirma "os iconoclastas na verdade queriam eliminar imagens da imaginação coletiva, porém conseguiriam somente destruir seus suportes midiáticos" (2006, p. 5).

A constatação de Belting (2006) não dá brechas para uma iconoclastia que se realiza de fato. Além do incremento simbólico das imagens destruídas, há que se levar em consideração a circunscrição midiática da maioria dos gestos desta natureza. Não havendo espaço para um gesto espetacular fora do horizonte midiático, o destino da destruição de imagens seria eternizar-se em imagens, constantemente rememorizadas e intensificadas.

A circularidade midiática da memória. Este último aspecto, intrinsecamente vinculado aos dois primeiros, refere-se à inscrição do gesto iconoclasta no tempo circular da mídia. 0 videoteipe dos preparativos da morte de Saddam Hussein, já exaustivamente exibidos na televisão, continuará a repetir-se no youtube. A reiteração constante e pública da destruição de uma imagem é expressão de uma ambivalência: o desejo compulsivo de perpetrar novamente 0 ato ou a necessidade de preservar a memória. Em todo caso, ainda veremos a cada 11 de setembro os aviões colidindo com as torres, seja pela sua rememoração nas páginas dos jornais, na TV, na internet e no próprio cinema. 0 cientista da mídia, Harry Pross (1980), considera que a sincronização social é uma das principais funções dos meios de comunicação de massa. Reatualizar a memória e ritualizar o calendário são mecanismos, 
neste caso, de retomada do gesto iconoclasta.

Das imagens em videoteipe ou das fotografias não é possível recompor os estilhaços. Para o telespectador, a imaterialidade da imagem física não lhe dá nenhum pedaço de concreto ou madeira como memorabilia, resta-lhe o consolo do replay.

A imortalização do gesto iconoclasta não se dará apenas pela sua migração para 0 universo da imagens, mas pela potencial repetição $a d$ eternum. A memória não será apenas do gesto, mas também da imagem violentada. Se Belting (2006) imagina a tolice dos iconoclastas pela migração das imagens para a imaginação pública e um possível ganho de sua força simbólica, nesta nova moldura a tolice permanece em razão da impossibilidade de fuga dos suportes imagéticos. No horizonte da visibilidade midiática, não haverá espaço para as sombras ou para invisibilidades, tudo fatalmente se transfigurará em imagens. A questão política das imagens não deverá mais se referir aos espaços de visibilidade e invisibilidade, mas sim delegar às imagens apenas maior ou menor visibilidade, uma vez que as sombras deixam de existir. A consequente reatualização dessas imagens não responde somente ao desejo de reviver os gestos iconoclastas, mas permitirá nosso desejo secreto de remontar às imagens quebradas. Enfim, os efeitos desejados pelo gesto iconoclasta estarão sempre fadados à frustração. Haverá algum consolo?

A nova condição midiática do iconoclasmo prova que ainda não é possível responder à questão de
Latour sobre a superação do ciclo de fascinação, repulsão, quebra e arrependimento. Erigir e destruir ídolos são práticas ainda ampliadas pelas mídias visuais. Para concluir, uma pista para entender a compulsão do espírito humano para destruir dada por Walter Benjamin:

0 caráter destrutivo é jovem e alegre. [...] 0 caráter destrutivo não vê nada duradouro. Mas exatamente por isso vê caminhos por toda a parte. Lá onde outros se deparam com muros ou montanhas, também lá ele vê um caminho. Mas porque ele vê um caminho em toda a parte, em toda a parte tem que desocupar o caminho. Nem sempre com violência bruta, às vezes com violência lapidada. Porque em toda a parte vê caminhos, está, ele próprio, sempre em encruzilhadas. Nenhum momento pode saber 0 que 0 próximo momento trará. 0 que está de pé ele deita em escombros, não por causa dos escombros, mas por causa do caminho que passa por meio deles (1975 apud BAITELLO JR., 1997, p. 116).

\section{Referências}

BAITELLO JR., Norval. A era da iconofagia. São Paulo: Hacker, 2005.

BAITELLO JR., Norval. 0 animal que parou os relógios. São Paulo: Annablume, 1997.

BAUDRILLARD, Jean. Power inferno. Porto Alegre: Sulina, 2003.

BAUDRILLARD, Jean. Simulacros e simulação. Lisboa: Relógio D’água, 1991.

BELTING, Hans. Likeness and presence. Chicago: The University of Chicago Press, 1994.

BELTING, Hans. Imagem, mídia e corpo: uma nova abordagem à iconologia. Ghrebh, São Paulo, n.8, 2006. Disponível em: <www.cisc.org.br >. Acesso em 02 maio 2009. 
BESANÇON, Alain. The forbidden image: an

intellectual history of iconoclasm. Chicago: The

Universe of Chicago Press, 2000.

BÍBLIA Sagrada. Tradução: João Ferreira de Almeida.

São Paulo: Sociedade Bíblica do Brasil, 2002.

BYSTRINA, Ivan. Tópicos de semiótica da cultura.

São Paulo: Centro Interdisciplinar de Semiótica da

Cultura e da Mída, 1995. (pré-print)

DENZINGER, Enrique. El magisterio de la Iglesia.

Barcelona: Herder, 1963.

DURAND, Gilbert. Imaginação simbólica. Lisboa:

Edições 70, 1990.

FLUSSER, Vilém. Filosofia da caixa preta: ensaios para uma futura filosofia da fotografia. Rio de Janeiro: Relume Dumará, 2002.

GARSIDE JR., Charles. Zwingli and the arts. New Haven: Yale University Press, 1966.

KAMPER, Dietmar. A estrutura temporal das imagens. In: GALENO, Alex; CASTRO, Gustavo de (orgs.).

Complexidade à flor da pele. São Paulo: Cortez, 2003. p.57-62.

LATOUR, Bruno; WEIBEL, Peter. Iconoclash.

Cambridge: MIT Press, 2002.

MORIN, Edgar. 0 paradigma perdido. Lisboa: EuropaAmérica, 1973.

PROSS, Harry. Estructura simbólica del poder.

Barcelona: G. Gili, 1980. 


\begin{tabular}{|c|c|}
\hline $\begin{array}{l}\text { Destroying images: } \\
\text { media configurations } \\
\text { of iconoclasm }\end{array}$ & $\begin{array}{l}\text { Destruyendo imágenes: } \\
\text { configuraciones mediáticas } \\
\text { del iconoclasmo }\end{array}$ \\
\hline $\begin{array}{l}\text { Abstract } \\
\text { This paper is an essay about the iconoclast } \\
\text { gesture and its circumscription in the media } \\
\text { horizon. It describes briefly some historical } \\
\text { episodes that dealt over controversies upon the } \\
\text { semiotic status of image and identifies three } \\
\text { aspects of the new conditions determined by the } \\
\text { culture of media: a) the demands of visibility; } \\
\text { b) the paradox of destruction; and c) the media } \\
\text { circulation of memory. We depart from the theory } \\
\text { of image elaborated by German scholar Hans } \\
\text { Belting and also from French philosopher Bruno } \\
\text { Latour's contributions. } \\
\text { Keywords } \\
\text { Media. Iconoclasm. Image. }\end{array}$ & $\begin{array}{l}\text { Resumen } \\
\text { Este artículo es un ensayo sobre el gesto } \\
\text { iconoclasta y su circunscripción en el horizonte } \\
\text { mediático. Él describe de forma panorámica } \\
\text { algunos episodios históricos de controversias } \\
\text { sobre el estatuto semiótico de la imagen e } \\
\text { identifica tres aspectos de las nuevas condiciones } \\
\text { impuestas por la cultura mediática: a) la } \\
\text { exigencia de visibilidad; b)el paradojo de la } \\
\text { destrucción; y c) la circularidad mediática de } \\
\text { la memoria. Nuestra perspectiva está basada } \\
\text { en la teoría de la imagen del estudioso alemán } \\
\text { Hans Belting y en las contribuciones del filósofo } \\
\text { francés Bruno Latour. } \\
\text { Palabras clave } \\
\text { Media. Iconoclasmo. Imagen. }\end{array}$ \\
\hline
\end{tabular}




\section{Expediente}

A revista E-Compós é a publicação científica em formato eletrônico da Associação Nacional dos Programas de Pós-Graduação em Comunicação (Compós). Lançada em 2004, tem como principal finalidade difundir a produção acadêmica de pesquisadores da área de Comunicação, inseridos em instituições do Brasil e do exterior.
E-COMPÓS I www.e-compos.org.br I E-ISSN 1808-2599

Revista da Associação Nacional dos Programas de Pós-Graduação em Comunicação. Brasília, v.12, n.2, maio/ago. 2009

A identificação das edições, a partir de 2008 passa a ser volume anual com três números.

\section{CONSELHO EDITORIAL}

\section{Afonso Albuquerque}

Universidade Federal Fluminense, Brasil

Alberto Carlos Augusto Klein

Universidade Estadual de Londrina, Brasi

Alex Fernando Teixeira Primo

Universidade Federal do Rio Grande do Sul, Brasil

\section{Alfredo Vizeu}

Universidade Federal de Pernambuco, Brasil

Ana Carolina Damboriarena Escosteguy

Pontifícia Universidade Católica do Rio Grande do Sul, Bras

Ana Silvia Lopes Davi Médola

Universidade Estadual Paulista, Brasil

André Luiz Martins Lemos

Universidade Federal da Bahia, Brasil

Ângela Freire Prysthon

Universidade Federal de Pernambuco, Brasil

Antônio Fausto Neto

Universidade do Vale do Rio dos Sinos, Brasil

Antonio Carlos Hohlfeldt

Pontifícia Universidade Católica do Rio Grande do Sul, Brasil

Arlindo Ribeiro Machado

Universidade de São Paulo, Brasil

César Geraldo Guimarães

Universidade Federal de Minas Gerais, Brasil

Cristiane Freitas Gutfreind

Pontifícia Universidade Católica do Rio Grande do Sul, Brasil

Denilson Lopes

Universidade Federal do Rio de Janeiro, Brasil

Eduardo Peñuela Cañizal

Universidade Paulista, Brasi

Erick Felinto de Oliveira

Universidade do Estado do Rio de Janeiro, Brasil

Francisco Menezes Martins

Universidade Tuiuti do Paraná, Brasil

Gelson Santana

Universidade Anhembi/Morumbi, Brasi

Hector Ospina

Universidad de Manizales, Colômbia

leda Tucherman

Universidade Federal do Rio de Janeiro, Brasil

Itania Maria Mota Gomes

Universidade Federal da Bahia, Brasil

Janice Caiafa

Universidade Federal do Rio de Janeiro, Brasil

Jeder Silveira Janotti Junior

Universidade Federal da Bahia, Brasil
João Freire Filho

Universidade Federal do Rio de Janeiro, Brasil

John DH Downing

University of Texas at Austin, Estados Unidos

José Luiz Aidar Prado

Pontifícia Universidade Católica de São Paulo, Brasil

José Luiz Warren Jardim Gomes Braga

Universidade do Vale do Rio dos Sinos, Brasil

Juremir Machado da Silva

Pontifícia Universidade Católica do Rio Grande do Sul, Brasil

Lorraine Leu

University of Bristol, Grã-Bretanha

Luiz Claudio Martino

Universidade de Brasília, Brasil

Maria Immacolata Vassallo de Lopes

Universidade de São Paulo, Brasil

Maria Lucia Santaella

Pontifícia Universidade Católica de São Paulo, Brasil

Mauro Pereira Porto

Tulane University, Estados Unidos

Muniz Sodre de Araujo Cabral

Universidade Federal do Rio de Janeiro, Brasil

Nilda Aparecida Jacks

Universidade Federal do Rio Grande do Sul, Brasil

Paulo Roberto Gibaldi Vaz

Universidade Federal do Rio de Janeiro, Brasil

Renato Cordeiro Gomes

Pontifícia Universidade Católica do Rio de Janeiro, Brasil

Ronaldo George Hela

Universidade do Estado do Rio de Janeiro, Brasil

Rosana de Lima Soares

Universidade de São Paulo, Brasil

Rossana Reguillo

Instituto Tecnológico y de Estudios Superiores do Occidente, México

Rousiley Celi Moreira Maia

Universidade Federal de Minas Gerais, Brasil

Sebastião Carlos de Morais Squirra

Universidade Metodista de São Paulo, Brasil

Simone Maria Andrade Pereira de Sá

Universidade Federal Fluminense, Brasil

Suzete Venturelli

Universidade de Brasília, Brasil

Valério Cruz Brittos

Universidade do Vale do Rio dos Sinos, Brasil

Veneza Mayora Ronsini

Universidade Federal de Santa Maria, Brasil

Vera Regina Veiga França

Universidade Federal de Minas Gerais, Brasil
COMISSÃO EDITORIAL

Ana Gruszynski I Universidade Federal do Rio Grande do Sul, Brasil Felipe da Costa Trotta I Universidade Federal de Pernambuco Rose Melo Rocha I Escola Superior de Propaganda e Marketing, Brasil

\section{CONSULTORES AD HOC}

Aníbal Francisco Alves Bragança I Universidade Federal Fluminense Benjamim Picado I Universidade Federal da Bahia

Carlos Eduardo Franciscato I Universidade Federal de Sergipe

Christa Liselote Berger I Universidade Vale do Rio dos Sinos

Gisela Castro I Escola Superior de Propaganda e Marketing

Luciana Pellin Mielniczuk I Universidade Federal de Santa Maria

Marcia Benetti I Universidade Federal do Rio Grande do Sul

Paulo Cunha Carneiro Filho I Universidade Federal de Pernambuco

Raquel Recuero I Universidade Católica de Pelotas

REVISÃO DE TEXTO E TRADUÇÃO I Everton Cardoso

EDITORAÇÃO ELETRÔNICA I Raquel Castedo
COMPÓS I www.compos.org.br

Associação Nacional dos Programas de Pós-Graduação em Comunicação

Presidente

Itania Maria Mota Gomes

Universidade Federal da Bahia, Brasil

itania@ufba.br

Vice-presidente

Julio Pinto

Pontifícia Universidade Católica de Minas Gerais, Brasil

juliopinto@pucminas.br

Secretária-Geral

Ana Carolina Escosteguy

Pontifícia Universidade Católica do Rio Grande do Sul, Brasil

carolad@pucrs.br 